\title{
FRAGMENTOS DE LA HISTORIA AMBIENTAL DEL SISTEMA DE FIORDOS Y CANALES NOR-PATAGÓNICOS, SUR DE CHILE: DOS SIGLOS DE EXPLOTACIÓN
}

\author{
CARLOS MOLINET'a ${ }^{\mathrm{a}}$ MARÍA EUGENIA SOLARI ${ }^{\mathrm{b}}$, \\ MANUEL DÍAZa, FRANCISCA MARTICORENAc ${ }^{c}$ PATRICIO A. DÍAZ ${ }^{\mathrm{d}}$, \\ MAGDALENA NAVARRO ${ }^{b} \&$ EDWIN NIKLITSCHEK
}

\begin{abstract}
RESUMEN
La información disponible sobre muchos de los cambios ambientales producidos en el Sistema de Fiordos y Canales Nor-Patagónicos se encuentra dispersa y en muchos casos limitada a los relatos y memorias de quienes habitaron, navegaron y/o trabajaron en la zona y, por lo tanto, son fragmentarios. Sin embargo, es posible reconstruir evidencia que indica una fuerte presión de explotación de estos ecosistemas en los últimos dos siglos, los que parecen haber modificado de manera significativa el paisaje terrestre y submarino. El patrón de explotación de recursos naturales ha sido sistemático pasando de una especie a otra (árboles, mamíferos, invertebrados, algas y peces), lo que sumado a la introducción de especies exóticas, ha resultado en la disminución significativa en la cobertura del bosque, la abundancia de aves y mamíferos marinos y de los stocks pesqueros.

El rico patrimonio ambiental que posee una superficie de 5.161.387 ha de áreas protegidas (80\% de la superficie de este litoral) parece estar pobremente valorado, lo que se puede explicar debido a su desconocimiento, por la difícil y costosa accesibilidad que presenta para quienes no buscan explotar sus recursos naturales.

Esta revisión tiene como objetivo describir y sintetizar parte importante de la información disponible, fragmentaria, acerca de las principales actividades humanas que motivaron y motivan la ocupación de este ecosistema litoral y sus principales efectos ambientales y transformaciones del paisaje. Finalmente se reflexiona sobre la relación de los habitantes y usuarios con el Sistema de Fiordos y Canales Nor-Patagónicos, sugiriendo cambios para promover la sustentabilidad de estos ecosistemas litorales.
\end{abstract}

PALABRAS CLAVE: patrimonio ambiental, explotación, paisaje, litoral norte de Aysén, Patagonia.

a Programa de Investigación Pesquera e Instituto de Acuicultura, Universidad Austral de Chile, Los Pinos s/n, Balneario Pelluco, Puerto Montt, Chile. $\ \backslash$ cmolinet@uach.cl

b Instituto de Estudios Antropológicos, Universidad Austral de Chile, Campus Isla Teja s/n, Valdivia, Chile.

c Magíster en Estudios Latinoamericanos, Universidad de Chile, lunamarticorena@gmail.com

d Centro i mar, Universidad de Los Lagos, Camino Chinquihue Km 7, Puerto Montt, Chile. 


\title{
FRAGMENTS OF THE ENVIRONMENTAL HYSTORY OF FJORD AND CHANNELS NORTH PATAGONIC SYSTEM, SOUTH OF CHILE: TWO CENTURIES OF EXPLOITATION
}

\begin{abstract}
The available information about the environmental changes produced in the Nor-Patagonian Fjords and Channels System is dispersed and, in several cases, limited to the narrations and memories of those who lived, navigated and / or worked in this area, and therefore are fragmentary. However, it is possible to identify evidence that indicates a strong exploitation pressure on these ecosystems in the last 2 centuries, which would had significantly modified their terrestrial and submarine landscape. The natural resources exploitation pattern was systematically incorporating species into a portfolio (trees, mammals, invertebrates, algae, fish), to the extent that they acquired economic value. This, added to the introduction of exotic species, resulted in a significant decrease in forest cover, the abundance of birds and marine mammals and effects on fish and shellfish stocks.

This rich environmental heritage that has an area of 5,161,387 ha of protected areas $(80 \%$ of this littoral surface) seems to be poorly valued, which can be explained due to its lack of knowledge, remoteness, and the difficult and expensive accessibility for those who do not seek to exploit their natural resources.

The aim of this review is to describe and synthesize an important part of the fragmentary available information about the main human activities that motivated and actually motivate the occupation of this coastal ecosystem and its main environmental effects and landscape transformations. Finally, we discuss about the inhabitants-users and the Nor-Patagonian fjords and channels system relationship, suggesting changes to promote the sustainability of these coastal ecosystems.
\end{abstract}

KEY WORDS: Environmental heritage, exploitation, landscape, Aysén littoral, Patagonia.

\section{INTRODUCCIÓN}

El sistema de islas, fiordos y canales del sur de Chile es uno de los más extensos del mundo y representa alrededor del $95 \%$ de la línea de costa del país. Desde una perspectiva ecogeográfica (Lancelloti \& Vázquez, 2000; Spalding et al. 2007; Viviani, 1979), este sistema forma parte del Archipiélago Patagónico, que a su vez puede ser dividido en tres eco-regiones principales: Nor-Patagónico, entre el Canal de Chacao y la Península de Taitao; Meso-Patagónico, entre la Península de Taitao y el Estrecho de Magallanes, y Sur-Patagónico, entre el Estrecho de Magallanes y el Cabo de Hornos (Martinic, 2004; Steffen, 1910). Desde un punto de vista oceanográfico (Niklitschek et al. 2013) y sociocultural (Martinic, 2005), los fiordos y canales de la eco-región Nor-Magallánica pueden ser divididos en dos grandes unidades de análisis de paisajes: el Mar Interior de Chiloé, entre el Canal de Chacao y el Golfo de Corcovado, y el
Sistema de Fiordos y Canales Nor-Patagónicos, entre el Golfo de Corcovado y la Península de Taitao. Dada su vinculación administrativa con la Región de Aysén, nos referiremos a esta unidad como el litoral Norte de Aysén (LNA).

Los patrones de explotación de los recursos naturales del Mar Interior de Chiloé y del Litoral Norte de Aysén han seguido una secuencia similar, que ha incluido la explotación del ciprés de las Guaitecas (Pilgerodendron uviferum), la caza de especies peleteras, la pesca y la acuicultura, principalmente. La temporalidad y magnitud del desarrollo de estas actividades es, sin embargo, muy distinta entre ambas zonas, así como también nuestra capacidad de describir y analizar sus impactos, ya que éstos han estado, en general, mejor documentados en el caso del Mar Interior de Chiloé, que en el del Litoral Norte de Aysén, donde la literatura es más escasa y dispersa (Martinic, 2005; Quiroz, 2014; Simpson, 1870; Torrejón et al. 2013). Esta falta de atención a la historia ambiental del Litoral Norte de Aysén 
contrasta con su importancia económica, social y ambiental, ampliamente reconocida durante la última década (Hucke-Gaete et al. 2004; Moreno et al. 2006; Niklitschek et al. 2013; Orensanz et al. 2005; Solari et al. 2012).

El Litoral Norte de Aysén estuvo habitado, desde épocas precolombinas (5.500/5.000 años $\mathrm{AP})$, por grupos humanos denominados canoeros, cuya adaptación a un estilo de vida marítimo solo ha podido ser estudiada de manera temporal y espacialmente fragmentada (Solari et al. 2012). Esta situación dificulta comprender y ubicar cronológicamente tanto la colonización del área, posiblemente desde el Archipiélago de Chiloé, como sus posibles relaciones de intercambio comercial y/o cultural, tanto con Chiloé como con los valles orientales, de Aysén y las zonas litorales ubicadas al sur de la Península de Taitao. Desde mediados del siglo XVI, con la llegada de las expediciones europeas y la posterior conquista española de Chile continental y de la Isla Grande de Chiloé, el Litoral Norte de Aysén pasó a representar un lugar de tránsito y conexión entre Chile continental y/o la Isla Grande de Chiloé y el Estrecho de Magallanes (Barros, 1981; García, 1766) (Fig. 1).

Siguiendo a Torrejón et al. (2013), parece razonable especular que los impactos ambientales de la actividad humana en la zona se incrementaron fuertemente a partir de la independencia de Chile. Los primeros registros de estas transformaciones ambientales de gran escala datan de finales del siglo XIX y corresponden a las explotaciones intensivas de sus recursos peleteros y madereros (Martinic, 2005; Simpson, 1870). Además, nuevas y profundas transformaciones afectan los fiordos orientales desde la primera mitad del siglo XX, dado el arrastre masivo de sedimentos y nutrientes derivado de la quema sistemática de $>3.000 .000$ de hectáreas para uso ganadero en las principales cuencas hidrográficas del LNA (Bizama et al. 2011; Quintanilla et al. 2015).

Las explotaciones madereras y peleteras dieron paso a la explotación pesquera, de ballenas (Quiroz, 2014), de mariscos y luego de peces, que se hicieron cada vez más intensivas, alcanzando máximos históricos a mediados de los años 1980s (Fig. 2). Coincidiendo con la disminución progresiva de cuotas y desembarques pesqueros, la acuicultura comercial de salmónidos comienza a crecer rápidamente y llega a ser la actividad productiva dominante en el litoral de Aysén durante las últimas dos décadas (O'Ryan et al. 2010). Más aún, y pese a sucesivas crisis sanitarias y económicas, es la única de las actividades mencionadas que se encuentra aún en expansión (Niklitschek et al. 2013).

El modelo de relación con la naturaleza instaurado por los diferentes grupos humanos que se fueron asentando en el litoral de Aysén, evolucionó desde una economía de subsistencia, presente en los grupos canoeros tradicionales, hacia una economía extractivista de orientación comercial, evidente desde finales del siglo XIX y cuyo mayor auge se registró hacia finales del siglo XX, durante la llamada "fiebre" de la merluza del sur Merluccius australis (Fig. 2).

Las migraciones motivadas por la explotación de los recursos naturales van modelando los paisajes terrestres y submarinos del Litoral Norte de Aysén. El paisaje terrestre recibe el impacto de los propios asentamientos humanos y de los cambios en la cobertura del bosque, y en la abundancia de fauna conspicua (aves y mamíferos, principalmente), así como también de la introducción de especies exóticas, como diversos animales domésticos, y más recientemente, el visón (Mustela vison) (Sandoval, 1994). Cambios en la abundancia de aves marinas conspicuas como el pato vapor (Tachyeres pteneres), el panchillo (Chloephaga hybrida) y el caiquén (Chloephaga poliocephala) que han pasado desde bandadas a contadas parejas de adultos (Observación personal CM).

Los paisajes submarinos van resultando afectados por la explotación de recursos bentónicos y demersales (Fig. 2), por la introducción de salmones y truchas, y finalmente por la acuicultura industrial, que impone múltiples presiones al ecosistema.

La ocupación del Litoral Norte de Aysén plantea múltiples interrogantes en términos del uso sustentable de los recursos naturales, los cambios que se han producido y el impacto que estas perturbaciones tuvieron y tendrán en los ecosistemas locales. Un enfoque que permite caracterizar los impactos sobre determinados ecosistemas es aquel derivado de la historia ambiental (González de Molina, 1993), que si bien surge desde la historiografía, permite incorporar 


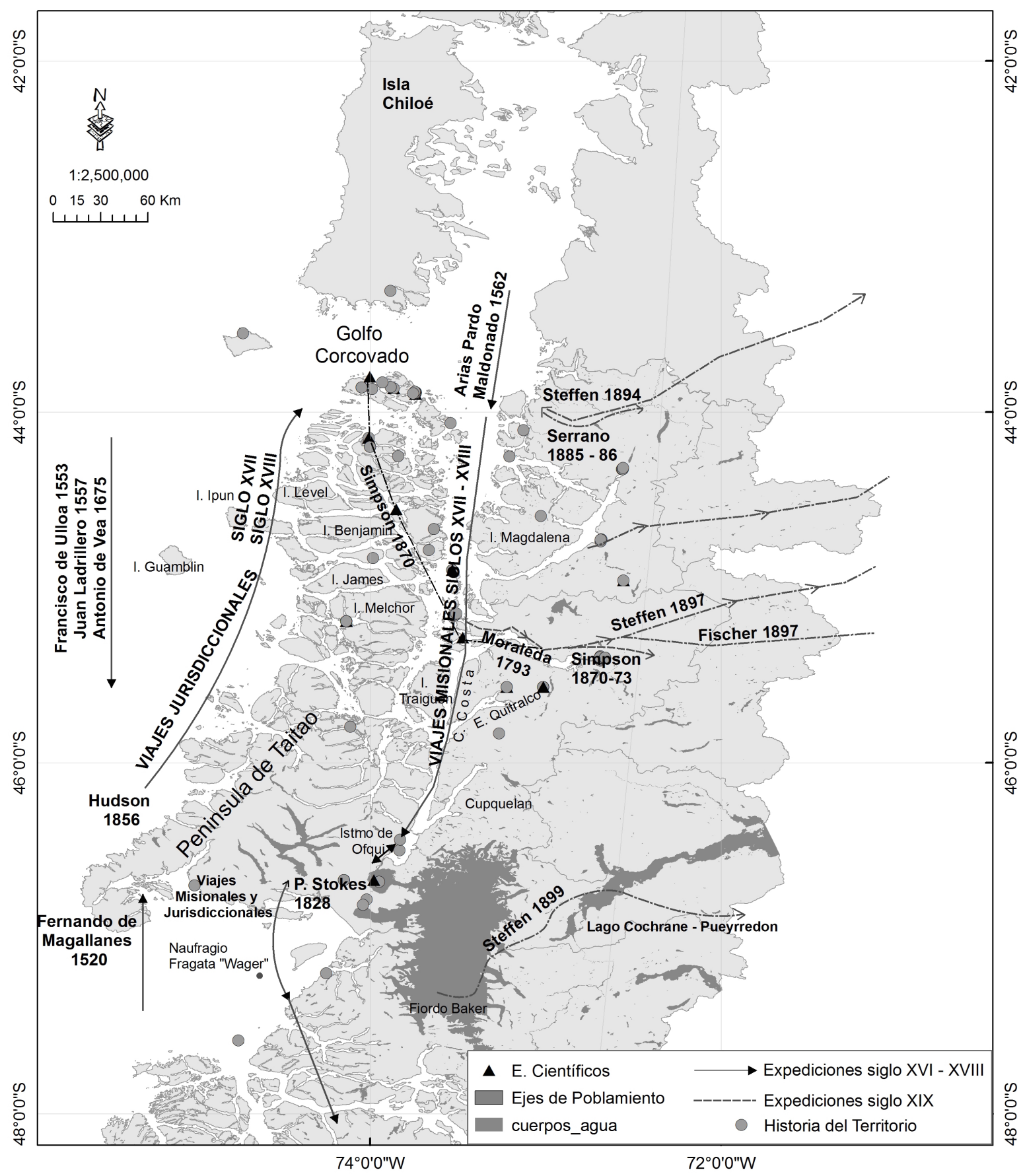

Fig. 1. Ejes del poblamiento y principales expediciones europeas realizadas desde mediados del siglo XVI en el litoral norte de la región de Aysén. Modificado de Martinic (2005).

una mirada interdisciplinaria del paisaje a lo largo de su ocupación. La historia ambiental aspira a hacer pertinente el análisis del medio ambiente a partir de la historiografía tradicional, llegando a relacionar la historia del clima, la historia económica, la evolución de los ecosistemas naturales y agrícolas, y la historia de la población, incorporando un diálogo con las ciencias naturales. 


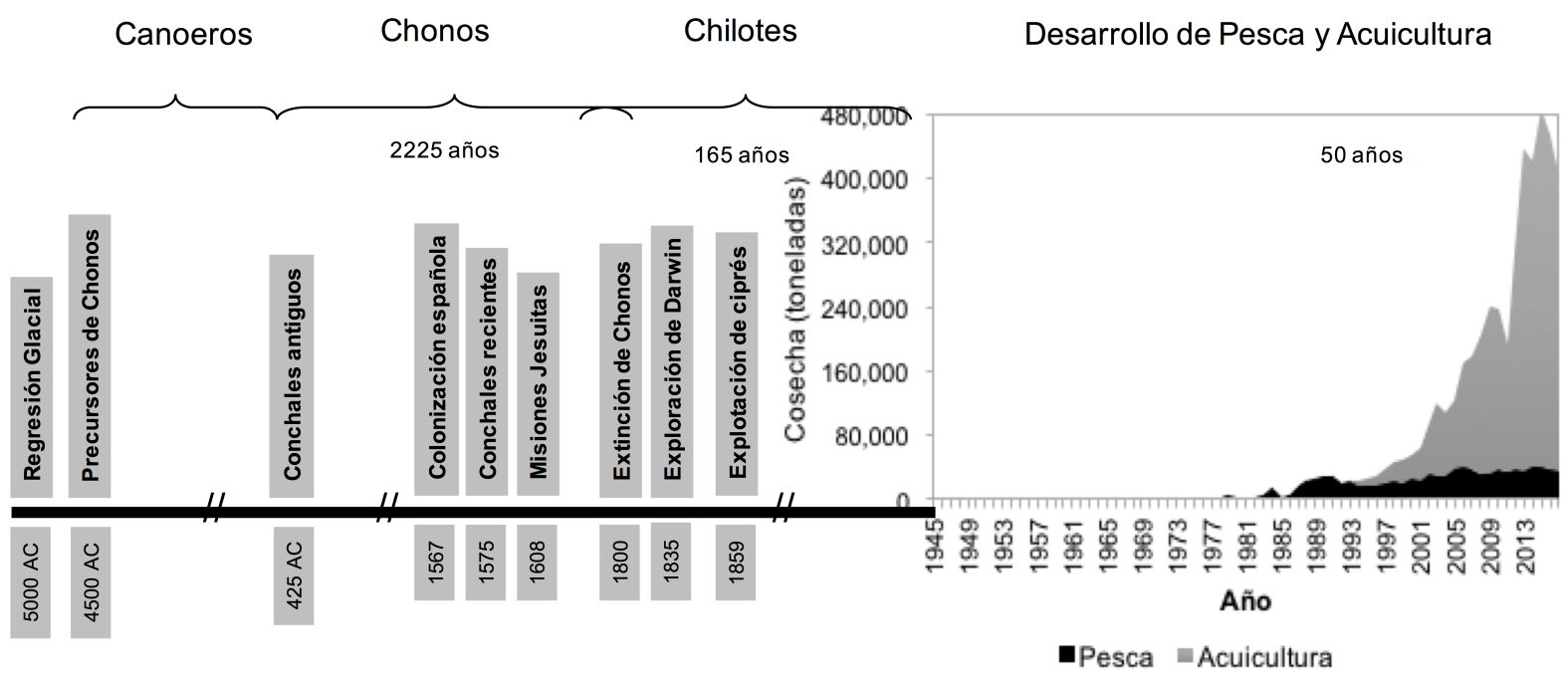

Fig. 2. Reconstrucción histórica y pesquera del Litoral Norte de Aysén (Modificado de Zuleta et al. 2005).

Los objetivos de esta revisión son: i) describir y sintetizar parte importante de la información disponible (y fragmentaria) acerca de las principales actividades humanas que motivaron y motivan la ocupación de las islas, fiordos y canales del LNA, ii) discutir $y$, en lo posible, proveer referencias cuantitativas sobre la magnitud de sus principales efectos ambientales y transformaciones del paisaje, $y$ iii) analizar las implicancias de estos efectos $y$ transformaciones para la sustentabilidad de los ecosistemas litorales. Para lograr estos objetivos, nos enfocamos en reconstruir parte de la historia ambiental del LNA, incluyendo una descripción espacial de las principales actividades productivas que motivaron su ocupación e intervención pasada y presente. Se incluye, además, un análisis y descripción de los principales efectos ambientales de la ocupación de este territorio.

\section{METODOLOGÍA}

Área de estudio

Para fines del presente estudio, definimos el Litoral Norte de Aysén como el conjunto de islas, fiordos y canales comprendidos entre el Golfo de Corcovado por el Norte $\left(43^{\circ} 45^{\prime} 00^{\prime \prime} \mathrm{S}\right)$ y la Península de Taitao por el Sur (46³0'00" S). Esta área comprende la totalidad de la comuna de Las Guaitecas, y parte importante de las comunas de Cisnes y Aysén. En ella se emplazan 11 comunidades litoraleñas (Fig. 3). El Litoral Norte de Aysén presenta cambios abruptos en su morfología costera y batimetría, donde la Boca del Guafo representa la principal entrada de agua oceánica a este sistema, la que fluye hacia el sur a través del Canal Moraleda y hacia el norte a través del Golfo de Corcovado (Pickard, 1971; Silva et al. 1995; Silva et al. 1998).

\section{Recopilación de información}

La recolección de información se realizó a través de revisiones bibliográficas, trabajo etnográfico, considerando documentación testimonial de primera fuente, viajes de exploración geográfica, publicaciones, informes de proyectos $y$ tesis. Lo anterior fue complementado con entrevistas no estructuradas a pobladores de las localidades de Melinka y Repollal, y sesiones de trabajo en que se documentó el conocimiento empírico proporcionado por los propios coautores del presente trabajo, quienes han habitado $\mathrm{y} / \mathrm{o}$ trabajado por varias décadas en el área de estudio. Esta información fue contrastada con aquella documentada en crónicas, mapas y otras fuentes documentales para reconstruir distintos elementos espaciales y ambientales reportados en el presente trabajo. La información sobre las pesquerías artesanales bentónicas y acuicultura se obtuvo de los anuarios estadísticos del Servicio Nacional de Pesca (Sernapesca, 1992-2010). También se 
consideró la información existente en reportes de pescas de investigación y el seguimiento de las pesquerías bentónicas realizado por el Instituto de Fomento Pesquero (IFOP), cuyos resultados para la zona describen y resumen Molinet et al. (2011); Molinet et al. (2008b). La distribución espacial de los caladeros de pesquerías demersales se obtuvo de las entrevistas a lugareños y de los reportes técnicos de Molinet and Niklitschek (1995) y Molinet et al. (2008b). La información sobre recursos forestales se obtuvo de distintos estudios realizados por CONAF, particularmente el "Catastro y evaluación de recursos vegetacionales nativos de Chile" (Corporación Nacional Forestal, 1999).

Las diversas fuentes de información utilizadas fueron identificadas siguiendo las siguientes convenciones: las fuentes bibliográficas fueron citadas de manera convencional y luego referenciadas en la sección correspondiente. La información obtenida mediante entrevistas fue identificada indicando "conocimiento local" y el nombre de la localidad donde éste fue registrado. La información proporcionada por los coautores fue identificada indicando "com. pers." y las iniciales del coautor correspondiente.

\section{Georeferenciación de la información}

La información obtenida fue ingresada a un sistema de información geográfica construido en ArcView y ArcGis 9.3, utilizando como sistema de geo-referencia el DATUM SIRGAS, siguiendo los estándares cartográficos del Sistema Nacional de Información Territorial. De esta manera se desplegó la distribución espacial de las principales actividades productivas realizadas en el área de estudio y los principales impactos asociados sobre el paisaje, entre otros mapas temáticos. Para estos mismos fines, la cobertura del bosque nativo fue representada sólo por el subtipo forestal ciprés de las Guaitecas (Pilgerodendron uviferum), dada la importancia ecológica, cultural y productiva de su especie característica. Este subtipo forestal fue clasificado en cuatro categorías: i) renoval, ii) adultorenoval, iii) adulto y iv) achaparrado (Tabla 1).

Con el resultado de las entrevistas se reconstruyeron las rutas de navegación y las áreas de explotación de cholga (Aulacomya atra), y se identificaron áreas generales de explotación de pieles de chungungo (Lontra felina) y huillín (Lontra provocax).

\section{RESULTADOS}

\section{La explotación del ciprés de las Guaitecas}

La cobertura del bosque nativo en el Litoral de Aysén, en años recientes alcanzaba un total de 2.900.000 ha, compuestas principalmente por el subtipo forestal siempre-verde y el subtipo ciprés de las Guaitecas (Fig. 3). La cobertura de este último subtipo en el área de estudio alcanza una superficie total de 447.246 ha (Tabla 1), lo que constituye un $3,3 \%$ de la superficie total ocupada por bosques nativos en el país. El subtipo forestal ciprés de las Guaitecas se ubica en las áreas altas, generalmente turberas, o en sectores planos de drenado restringido y extremadamente húmedos, entre los $39^{\circ} 35^{\prime} \mathrm{S}$ y los $54^{\circ} \mathrm{S}$ (Donoso, 1995). En las islas de los archipiélagos, ubicados al sur de Chiloé, crece generalmente en el centro de las islas o en algunos sectores planos cerca de los canales (Pisano, 1977). El ciprés de las Guaitecas es una especie de muy lento crecimiento, con incrementos medios anuales en altura de sólo $5,8 \mathrm{~cm}$ /año (Plaza, 2001). De esta manera, los actuales renovales que miden entre 2 y $8 \mathrm{~m}$ tendrían edades aproximadas entre 35 y 140 años, respectivamente.

Según la información etno-botánica disponible, el ciprés de las Guaitecas prestó gran utilidad a la cultura de los Kawésqar y probablemente de los Chonos, siendo de principal importancia como combustible para encender el fuego (Emperaire, 1963). Otros usos dados por las primeras culturas a esta conífera fueron la confección de remos y la construcción de embarcaciones y viviendas. Con el objeto de obtener leña seca y acceder a los bosques ubicados en el centro de las islas, los primeros habitantes del Litoral de Aysén ya habrían practicado la técnica de incendiar grandes paños de bosque (Simpson, 1870; Cruz \& Lara, 1981).

La madera de ciprés de las Guaitecas es particularmente aromática, presenta baja densidad y alta resistencia a la degradación natural. Estas características favorecieron su uso para la construcción de embarcaciones, durmientes de ferrocarril, estacas de cercos, postes de transmisión, 
Tabla 1. Superficie total (ha) para las cuatro categorías del subtipo forestal ciprés de las Guaitecas (Pilgerodendron uviferum) presentes en la provincia de Aysén, Sistema Nacional de Áreas Protegidas del Estado (SNASPE) y a nivel nacional.

\begin{tabular}{lccc}
\hline \multirow{2}{*}{ Tipo de bosque } & & Superficie & \\
\cline { 2 - 4 } & Provincia de Aysén & SNASPE & Nacional \\
\hline Bosque adulto & 44.869 & 202.715 & 243.845 \\
Renoval & 350.468 & 272.427 & 377.787 \\
Bosque adulto-renoval & 277 & 7.055 & 18.552 \\
Bosque achaparrado & 51.632 & 196.160 & 330.142 \\
\hline Total (ha) & 447.246 & 678.357 & 970.326 \\
\hline
\end{tabular}

Fuente: CONAF-CONAMA (1999).

rodrigones de viñas, madera aserrada y estructural para la construcción, y llevaron a que su demanda se incrementara fuertemente durante la segunda mitad del siglo XIX (Cruz \& Lara, 1981; Otero, 2006).

De acuerdo a Martinic (2005), el ciprés de las Guaitecas comenzó a ser explotado masivamente para la fabricación de durmientes de ferrocarril hacia 1860, probablemente por Felipe Westhoff, fundador de Melinka, el primer poblado del área de estudio. Simpson (1870) indica que, en 1870, Westhoff ocupaba cerca de 3.000 hombres en la producción de unos 300.000 durmientes $\left(\sim 22.500 \mathrm{~m}^{3}\right)$ de ciprés al año. Entre 1880 y 1920, la explotación del ciprés en el Litoral de Aysén pasa a ser liderada por Ciriaco Álvarez, quien supera los niveles de producción de Westhoff. La actividad se proyecta hasta avanzado el siglo XIX. Durante 1957-58, por ejemplo, se informaba la extracción de 2.000.000 $\operatorname{pies}^{3}\left(\sim 150.000 \mathrm{~m}^{3}\right)$ de ciprés de las Guaitecas.

El evidente deterioro de los bosques de ciprés de las Guaitecas llevó a la Convención sobre el Comercio Internacional de Especies Amenazadas de Fauna y Flora Silvestres (CITES) a incorporar esta especie en el Apéndice I desde el año 1973, lo que implicó el fin de su comercio internacional a partir de ese mismo año (www.cites.org).

Considerando un rendimiento promedio de 4,26 m3/árbol (Cruz \& Lara, 1981), es posible estimar que no menos de 5.200 árboles/año eran utilizados para la fabricación de durmientes en 1870 y no menos de 35.300 árboles/año en 1957. El impacto ambiental de esta explotación excedió, no obstante, y por mucho, el número de árboles aserrados, ya que la explotación estaba precedida por quemas extensivas destinadas a abrir paso y despejar los cipresales (Simpson,
1870; Cruz \& Lara, 1981), originando grandes incendios y destruyendo áreas continuas de miles de hectáreas. Simpson (1870, pp. 46-47) reporta que: por un árbol que se aprovecha se destruyen a lo menos diez, sin contar retoños, y esto no es exageración. Informa, asimismo haber observado islas enteras y más de 200 millas de bosques quemados durante sus expediciones y, afirma que, esto es una pequeña parte del todo. Mientras que la magnitud del impacto de la explotación del ciprés de las Guaitecas sobre el ecosistema no ha sido cuantificada, es posible estimar que alcanzó una extensión de al menos 148.280 ha, equivalente a un $96.4 \%$ de la superficie total ocupada por esta especie en el litoral norte de la región y calculada a partir de los 514.106 ha de bosques de este subtipo forestal que incluye otras 5 especies (Nothofagus antarctica, N. betuloides, N. nitida, Tepualia stipularis, Drimys winteri). Actualmente, sólo un 3.6\% corresponde a bosque adulto de esta especie (Fig. 3). El impacto más dramático de la explotación del ciprés, sin embargo, parece no haber sido sobre el ecosistema sino que sobre los últimos chonos habitando en el área de estudio (Martinic, 2005). De acuerdo a Simpson (1870, p. 43): Todos los restos y vestigios de esta raza ya casi han desaparecido a mano de los brutales hacheros, quienes tienen a mérito destruir todo lo que encuentran de esos, para ellos, abominables gentiles.

\section{La explotación del Sphagnum}

Asociado al hábitat del ciprés se puede observar una abundante cobertura de musgos del género Sphagnum (González-Espinosa et al. 


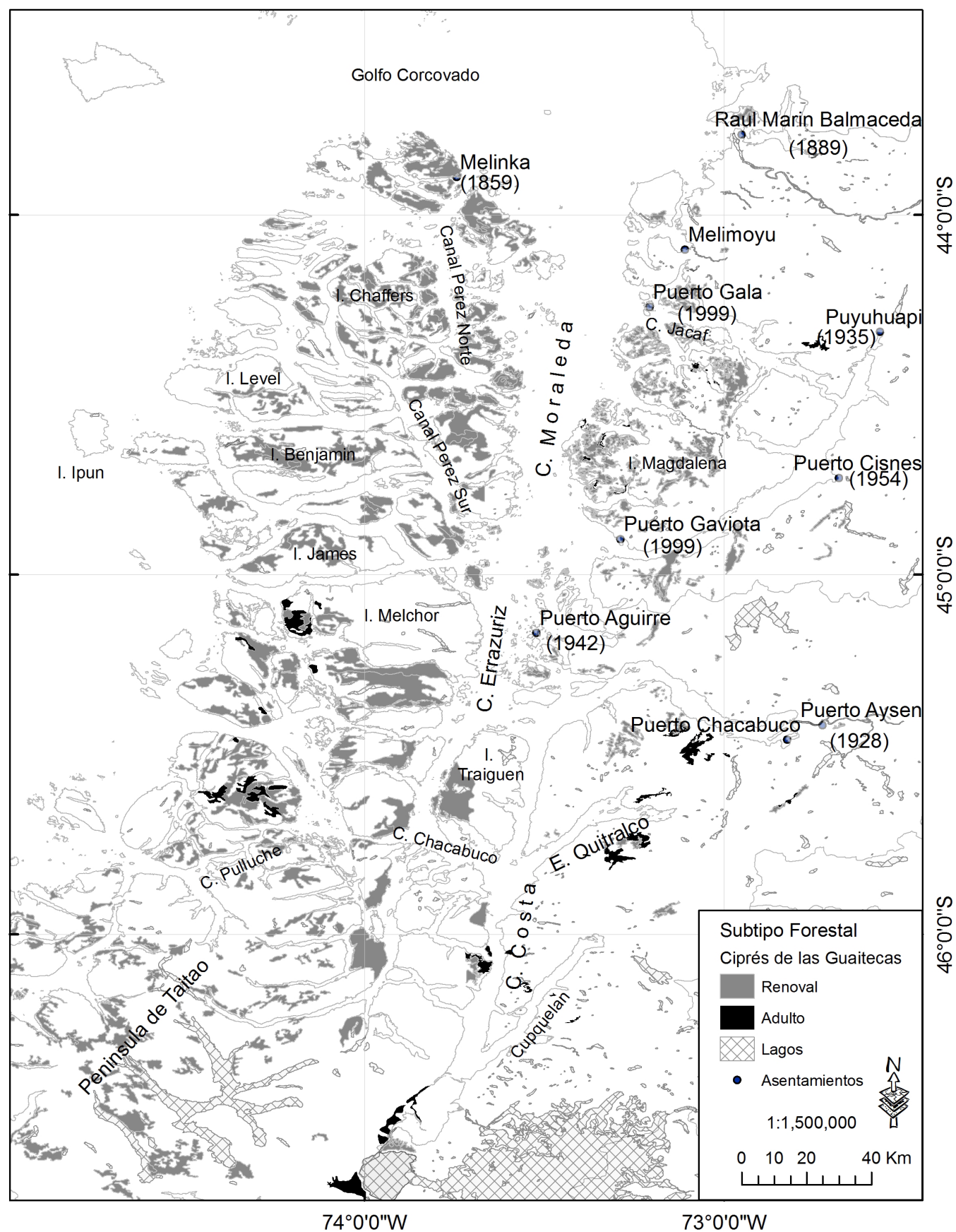

Fig. 3. Localización de los principales asentamientos del Litoral Norte de Aysén y extensión geográfica del subtipo ciprés de las Guaitecas. En paréntesis se muestra el año de fundación de cada localidad.

2007), los que en años recientes se han comenzado a explotar comercial e intensivamente (com. pers. CM), para diversos usos en países como Japón, Corea del Sur, Estados Unidos y Taiwán. Estas especies modulan la humedad ambiental, absorbiendo el exceso de agua mientras llueve y liberando esta agua lentamente cuando el aire se hace más seco. Su rol, protegiendo el suelo de inundaciones violentas y abasteciendo de agua durante los meses de verano a los ríos y arroyos 
que las desaguan (Glime, 2007), es fundamental en ambientes de delgada capa vegetal como lo son las islas de este litoral. Por lo tanto, su cosecha puede tener consecuencias negativas graves para el abastecimiento hídrico de los asentamientos humanos costeros, así como sus efectos sobre la diversidad biológica, el paisaje y la calidad de los suelos afectados. Para prevenir impactos negativos mayores, se hace prioritario el manejo de esta nueva actividad productiva en un contexto de sustentabilidad y la realización de estudios para una mejor comprensión de los procesos biológicos que ocurren en estos ecosistemas.

\section{La caza de mamíferos marinos}

La caza de lobo común (Otaria flavescens), lobo fino (Arctocephalus australis), elefante marino (Mirounga leonina) y foca leopardo (Hidrurga leptonyx) se orientó, principalmente, a la producción de aceite y cuero, y a la extracción de guano desde las loberas (Simpson, 1870; Acevedo et al. 2016). Posteriormente, cobra importancia la explotación de otras especies peleteras, incluyendo chungungo (Lontra felina), huillin (Lontra provocax) y coipo (Miocastor coipus) (Sielfeld, 1983; conocimiento local Melinka y Repollal). La caza comercial de mamíferos marinos se sumó a la caza para subsistencia que ya era tradicional, y de gran importancia para la alimentación, uso medicinal (de aceite de lobo y de aceite de huillín) y abrigo, para los primeros habitantes del Litoral de Aysén (Martinic, 2005; Marticorena, 2009; Torrejón et al. 2013). Esta cacería para autoconsumo fue continuada por los inmigrantes chilotes, quienes continúan practicando la cacería de popes de lobo común hasta el presente, principalmente, en el Archipiélago de Los Chonos (conocimiento local Melinka y Repollal). La actividad se concentra en los meses de verano, cuando los popes son faenados y ahumados para su posterior consumo durante el año (com. pers. $\mathrm{CM}$, conocimiento local Melinka).

La literatura sobre la caza de mamíferos marinos es fragmentaria y por lo general forma parte de relatos referidos a otros temas (Cárdenas, 1971; Montiel, 2003; Acevedo et al. 2016). La cacería seguía técnicas devastadoras (Simpson, 1870). En uno de sus relatos Montiel (2003, pp.
182-193), por ejemplo, describe ...el caso de las cuadrillas de loberos que en chalupas, lanchas o botes, con garrotes, escopetas y pólvora, se descolgaban por roquerios hacia cuevas o piedras gigantescas, donde se encontraban pariendo cientos de lobas, haciendo su entrada sigilosamente y comenzando una carnicería terrible, derribando a las lobas madres, algunas de las cuales resistian hasta 7 chuecazos o golpes con un palo grueso o estacón antes de morir.... La caza comercial de mamíferos en el área de estudio fue desarrollada por naves chilotas y extranjeras de mayor calado (Torrejón et al. 2013) y parece haber alcanzado un máximo durante el siglo XIX.

Aunque no existen registros acerca de la magnitud que esta actividad llegó a alcanzar, es probable que haya conducido a la extinción local de algunas especies como el elefante marino y la foca leopardo, y una severa reducción de la abundancia de lobo fino (Oporto et al. 1999; Martinic, 2005; Torrejón et al. 2013; Acevedo et al. 2016). Otaria flavescens (lobo común) registraba alrededor de 15.000 individuos en el LNA en los años 1990s (Oporto et al. 1999). En la actualidad, la cacería comercial de mamíferos marinos está prohibida, aunque para el caso del lobo común éste se encuentra en veda, condición que se ha renovado sucesivamente desde 2009, aunque con permisos específicos de pesca. Aún sin poder estimar su magnitud, fue posible utilizar el conocimiento local y los registros bibliográficos para reconstruir las áreas de acción más recientes de las cuadrillas de cazadores (Fig. 4), las que estuvieron concentradas principalmente en el archipiélago de Los Chonos, al oeste de los canales Pérez Norte y Pérez Sur para el caso de la nutria común (L. felina), mientras que en el caso de la nutria fina (L. provocax) la cacería comercial se desarrolló en las costas este y oeste de los canales Moraleda y Costa (Simpson, 1870; Torrejón et al. 2013; conocimiento local Melinka y Repollal).

\section{La explotación ganadera tierra adentro}

Aunque a veces ignorada respecto de sus efectos sobre los ecosistemas fluviales y marinos, el desarrollo de la ganadería en los valles centrales de la Región de Aysén afectó y sigue afectando de manera relevante los fiordos orientales del LNA. A 


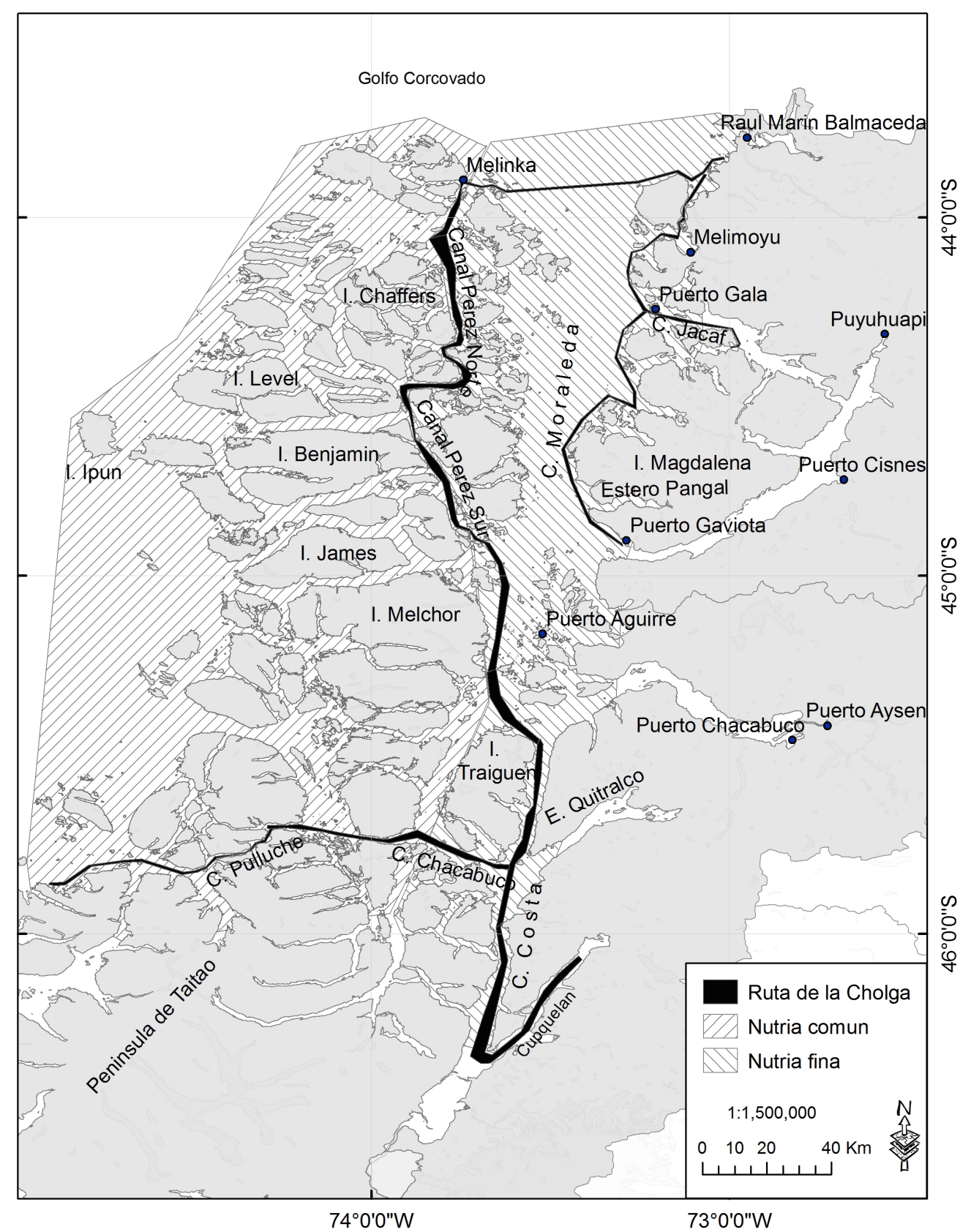

Fig. 4. Localización geográfica de las áreas de acción más recientes de las cuadrillas de "cazadores" en el litoral norte de la región de Aysén, complementada con la reconstrucción de la Ruta de la Cholga.

partir del inicio de la colonización de estos valles, en las primeras décadas del siglo XX (Martinic, 2005), se produce la quema y remoción sistemática de unas 3.5 millones de ha de bosques y matorrales en las cuencas de los principales ríos de la Región de Aysén: Palena, Cisnes, Aysén y Baker (Bizama et al. 2011; Quintanilla et al. 2015). Dichas quemas buscan facilitar la explotación ganadera del territorio, aun cuando gran parte de los suelos del área afectada no presenta características adecuadas para tales fines. De esta manera, se desencadena un proceso de erosión severa que 
sigue afectando hoy en día $>75 \%$ de esta superficie (CIREN, 2010). Aunque los aportes acumulados de sedimentos y nutrientes erosionados a los ríos y fiordos asociados a cada una de estas cuencas no han sido aún cuantificados, la magnitud de los mismos se hace evidente en el embancamiento progresivo de áreas litorales estuarinas, como la del otrora puerto de Puerto Aysén (Fig. 5, Sade \& Pérez, 2009).

\section{Explotación pesquera}

Junto a la carne de lobo, los pescados y principalmente mariscos fueron la base de la alimentación de los primeros habitantes del Litoral de Aysén. La evidencia proporcionada por los conchales sugiere que estos primeros habitantes tendieron a seguir un patrón general de explotación y abandono de los bancos locales, lo que podría ser visto como una estrategia tácita de explotación rotativa. Aunque esta estrategia no parece muy distinta de la que intuitivamente siguieron los habitantes más recientes de esta misma área, es evidente que ella perdió sustentabilidad en la medida en que aumentó la frecuencia e intensidad de las revisitas en las actividades de pesca, sobre todo cuando la explotación se tornó en una actividad comercial.

Ya en 1870, existía una planta conservera en Puerto Americano, con una producción anual de 25.000 latas (Martinic, 2005). A partir de 1929 se comienza a visualizar en el Litoral Norte de Aysén un interés por la alta concentración de recursos bentónicos, esencialmente mariscos, que existían en la zona (Sernapesca, 1990). Entre 1948

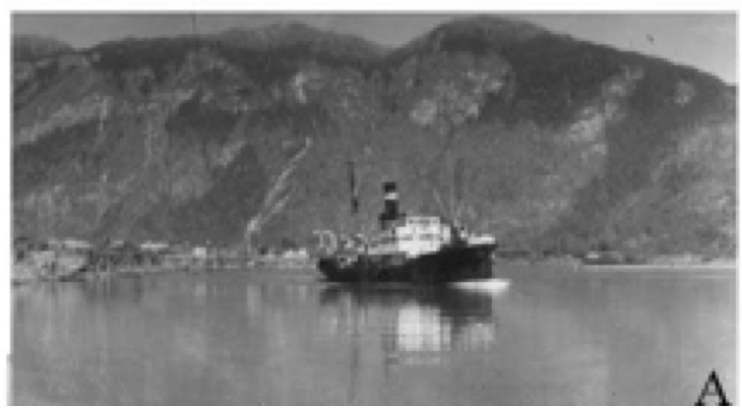

y 1950 se instalan en Puerto Aguirre y Melinka tres nuevas industrias pesqueras, todas dedicadas al procesamiento de choros, choritos, cholgas, erizos y otros mariscos (Sernapesca, 1990).

Aun cuando las primeras estadísticas pesqueras nacionales se remontan al año 1956, sólo a partir de 1967 se incorpora la Región de Aysén como unidad estadística oficial, año en el que desembarcaron 433 tons dominadas por moluscos bivalvos (70\%), peces (18\%), erizos $(9 \%)$ y crustáceos (3\%). El desembarque regional ese año contribuyó con sólo un $0.01 \%$ del desembarque nacional. En 2010 el desembarque artesanal de la XI región alcanza alrededor de 15.000 tons, dominado por erizos (50\%), peces $(40 \%)$, algas (16\%) y moluscos $(9 \%)$, representando un $1 \%$ del desembarque nacional. Desde el año 2013 el desembarque parece haberse mantenido en torno a 20.000 tons, equivalente al $1.4 \%$ del desembarque nacional durante ese año. En 2016 este desembarque fue dominado por erizos (34\%), sardina austral (27\%) y algas (25\%). No obstante, se reconocen deficiencias en el registro de desembarques de la región de Aysén, los que podrían estar subestimados en beneficio de la región de Los Lagos.

Las primeras pesquerías comerciales estuvieron concentradas inicialmente en la captura de cholga Aulacomya atra, que se extraía en la zona desde fines del siglo XIX. Este recurso era ahumado y comercializado en todo el sur de Chile. La primera técnica de extracción comercial fue el gancho o palde, que permitía extraer "matas" de cholga desde la orilla (conocimiento local Melinka). Esta actividad se realizaba por familias

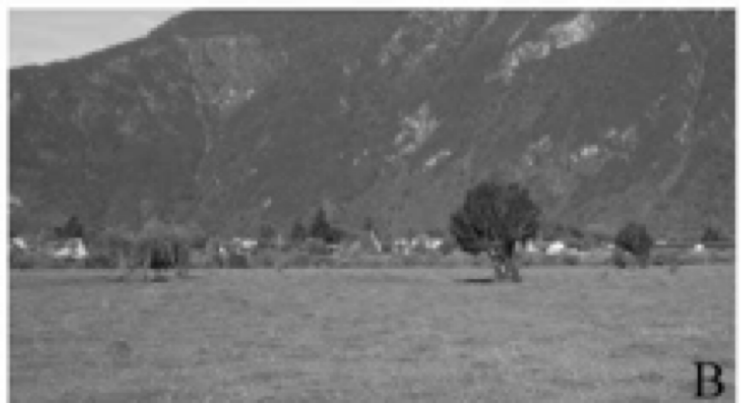

Fig. 5. A=Vista norte-sur del cauce del Río Aysén antes de 1969. En el centro, el vapor "Trinidad» en 1949, al fondo el Cerro Cordón. $\mathrm{B}=$ Aspecto actual del río. Se puede apreciar la ausencia del cauce en el lugar donde transitaban las embarcaciones y la sucesión de plantas y árboles que ha tomado lugar sobre los sedimentos tras el embancamiento (copiado de Sade \& Pérez, 2009 con permiso del autor correspondiente). 
completas, involucrando a hombres y mujeres, e implicaba el traslado por temporadas a los sitios de extracción. Otro producto que se ahumaba para su posterior comercialización era el róbalo (Eleginops maclovinus), que se sigue capturando con redes de enmalle en zonas costeras. Ambos productos (cholga seca y róbalo ahumado) siguen siendo ahumados y comercializados en su forma tradicional en el sur de Chile.

A mediados del siglo XX se incorporó la tecnología de buceo escafandra en Chiloé (Chambeaux et al. 2009), la que también llegó al litoral de Aysén y permitió incrementar la presión extractiva y el rango de profundidad impactado por la pesquería. Hasta finales de 1970, la mayor parte de la flota pesquera artesanal estaba constituida principalmente por chalupas propulsadas a remo y vela (com. pers. CM, conocimiento local Melinka y Repollal). Aunque la falta de motores no impidió que los pescadores del archipiélago recorrieran buena parte de la zona, en lo que se denominó la Ruta de la Cholga (Fig. 4).

Entre 1979 y 1981 la creciente demanda por erizo (Loxechinus albus) incentivó la incorporación del buceo hooka y la masificación del uso de motores para propulsar las embarcaciones, pasando de no más de 5 embarcaciones equipadas a más de 40 (com. pers. CM). Estos cambios tecnológicos produjeron un aumento considerable del esfuerzo pesquero $y$, por lo tanto, de los desembarques (Fig. 2). Esto facilitó que la flota bentónica de las regiones de Los Lagos y de Aysén desarrollaran, a partir de los 1980s, un modelo de explotación intensivo y sistemático basado en "faenas" o campamentos (Orensanz et al. 2005), levantados transitoriamente en prácticamente todo el litoral y concentrados principalmente en la captura de erizo (Fig. 6). La explotación de bivalvos como almejas y culengues también se intensifica desde la década de 1980, aunque los registros son más restringidos (ver anuarios de pesca en: http:// www.sernapesca.cl/index.php?option=com_remo sitory\&Itemid $=54 \&$ func $=$ select\&id $=2$ ).

A partir de los años 1980s comienza la explotación intensiva de peces demersales, principalmente de merluza austral (Merluccius australis) y, secundariamente, de congrio dorado (Genypterus blacodes), originando lo que se denominó "la fiebre de la merluza" (Aránguiz,
1992). Este desarrollo explosivo estimuló el ingreso masivo de personas, generando un poblamiento "espontáneo" de varias islas y sectores alrededor de los canales Moraleda y Costa, donde proliferaron más de una docena de campamentos de plástico (Moraga \& Moreno, 1995) (Fig. 6). Estos campamentos llegaron a albergar una población flotante de más de 5.000 personas (Aránguiz, 1992) provenientes de múltiples orígenes geográficos y socio-culturales, muchos de los cuales retornaron a sus lugares de procedencia en la medida que la rentabilidad de la explotación disminuye. De esta manera, sólo dos de estos campamentos se transformaron en localidades permanentes, Puerto Gala y Puerto Gaviota, las que en 2015 albergaban una población de 282 y 346 habitantes, respectivamente (http:// www.municipalidadcisnes.cl/index.php/comuna/ localidades/grupogala).

El esfuerzo artesanal sobre la merluza llegó a ser equivalente al de la flota industrial que operaba en el océano costero y produjo un impacto evidente sobre la abundancia local de la especie objetivo, cuya captura cayó desde un máximo histórico de 11.000 tons en 1983, a niveles de 4.000 a 1.000 tons en los últimos 5 años. El impacto de esta intensa actividad pesquera sobre otras especies no ha sido cuantificado, pero llevó a una evidente reducción en la presencia y abundancia relativa de especies simpátricas, capturadas incidentalmente en los espineles de merluza austral. La más evidente de esas reducciones correspondería a merluza de cola (Macruronus magellanicus) (com. pers. EN), especie para la que el Litoral de Aysén representa una importante área de alimentación prereproductiva (Niklitschek et al. 2014). A partir del año 2012 una nueva pesquería, la sardina austral, irrumpe en el LNA y pasa a ocupar un rol de gran importancia en términos de volumen, aunque sin llegar a superar todavía la importancia económica (valor total en playa y/o del producto final) y social (número total de pescadores involucrados) de la merluza austral.

\section{La introducción de especies}

La introducción de especies exóticas invasoras es en la actualidad, una de las principales causas del deterioro ambiental y pérdidas de 
biodiversidad en el sur de Chile (Iriarte et al. 2005). Representan además una de las principales causas de extinción de las especies nativas, las cuales sucumben rápidamente cuando se introducen este tipo de animales depredadores (Jaksic et al. 2002; Vitousek et al. 1996).

\section{a. Visón (Mustela vison)}

El visón es originario de Canadá y Estados Unidos de América y fue introducido como resultado de múltiples escapes y/o liberaciones intencionales de planteles peleteros establecidos en la Región de Aysén y otras zonas de Chile y Argentina, durante el siglo XX (Fasola et al. 2010; Rozzi \& Sherriffs, 2003; Sandoval, 1994). Aunque esta introducción se produjo en la zona continental, el visón alcanzó rápidamente el litoral y su avistamiento es hoy frecuente en todo el litoral de Aysén, al menos, desde las Islas Guaitecas y Raúl Marín Balmaceda por el norte hasta las Islas Canquenes por el sur (com. pers. CM, conocimiento local Melinka). El visón posee muchos de los atributos característicos de las especies exóticas invasoras: alta tasa reproductiva, hábitat y/o dieta de tipo generalista, alta capacidad de dispersión y asociación con el ser humano (Lodge, 1993; Sandoval, 1994). Es además un voraz depredador que se ha visto favorecido por la reducida abundancia de mamíferos carnivoros nativos. Aunque la sobreposición dietaria entre el visón y el huillin es variable entre localidades y parece ser menor en la Patagonia chilena que en la argentina (Fasola et al. 2009; Medina, 1997), se presume que el visón habría afectado negativamente la abundancia tanto de huillin, como de coipo, en Argentina (Pagnoni et al. 1986) y en Chile (Ruiz et al. 1996). El visón también depreda sobre huevos y polluelos de distintas especies de aves (Schüttler et al. 2009) y es considerado una de las mayores amenazas a la biodiversidad de aves acuáticas de la Patagonia (SAG, 1999). Aunque su impacto no ha sido estudiado en detalle, existe evidencia de que una menor abundancia de aves acuáticas afectaría a lagos invadidos por visón en la Patagonia argentina (Pescador et al. 2012).

\section{b. Truchas y salmones}

Después de más de un centenario de introducciones reiteradas en Chile y Argentina (Basulto, 2003; Bluth et al. 2003), salmones y truchas, principalmente de los géneros Salmo y Oncorhynchus, han llegado a ser comunes y relativamente abundantes en lagos, ríos, sistemas estuarinos y zonas costeras del cono sur de América y, en particular, de toda la Región Patagónica (Soto et al. 2006). Los primeros esfuerzos, iniciados en el siglo XIX, se enfocaron y tuvieron éxito en introducir especies de interés recreativo como trucha café Salmo trutta y arco iris Oncorhynchus mykiss. Más aún, esfuerzos de introducción y/o "repoblamiento", autorizados y no autorizados, públicos y privados, continúan afectando hoy los ecosistemas acuáticos de la Patagonia occidental y oriental, al menos, en la isla de Tierra del Fuego, la Región de Los Lagos y otras zonas de Argentina y Chile.

Entre los años 1970-1990s, liberaciones reiteradas de millones de alevines buscaron establecer poblaciones salvajes explotables ("ranching") de salmón chinook Oncorhynchus tsawytcha en Curaco de Vélez (Región de Los Lagos) y Río Prat (Región de Magallanes), y de salmón perro $O$. keta, salmón cereza $O$. masou y salmón rosado O. gorbuscha en la cuenca del Río Aysén (Niklitschek et al. 2013). Aunque ninguno de los esfuerzos de ranching fue comercialmente exitoso, el salmón chinook llegó a invadir completamente la Patagonia. Más aún, la distribución y abundancia de esta especie parece continuar en aumento (com. pers. EN), favorecida por la gran plasticidad de su ciclo de vida (Araya et al. 2014) y por las inexplicables restricciones a su captura impuestas por la reglamentación pesquera chilena.

A partir de los años 1980s, el desarrollo de la acuicultura industrial de salmónidos gatilla una tercera oleada invasora que afecta los ecosistemas litorales de Aysén a través de los escapes accidentales, pero reiterados, de millones de salmones y truchas cada año. La magnitud total estimada de los escapes de salmón del Atlántico Salmo salar, trucha arco iris Oncorhynchus mykiss y salmón coho O. tsawytscha en el Litoral Norte de Aysén, alcanzaba a 4,4×106 individuos en 2012 (Soto et al. 2001; Niklitschek et al. 2013), cifra que habría aumentado significativamente dado el aumento de la producción en años más recientes. Mientras que no existe evidencia de que se hayan establecido poblaciones asilvestradas de salmón atlántico y salmón coho, los individuos escapados 


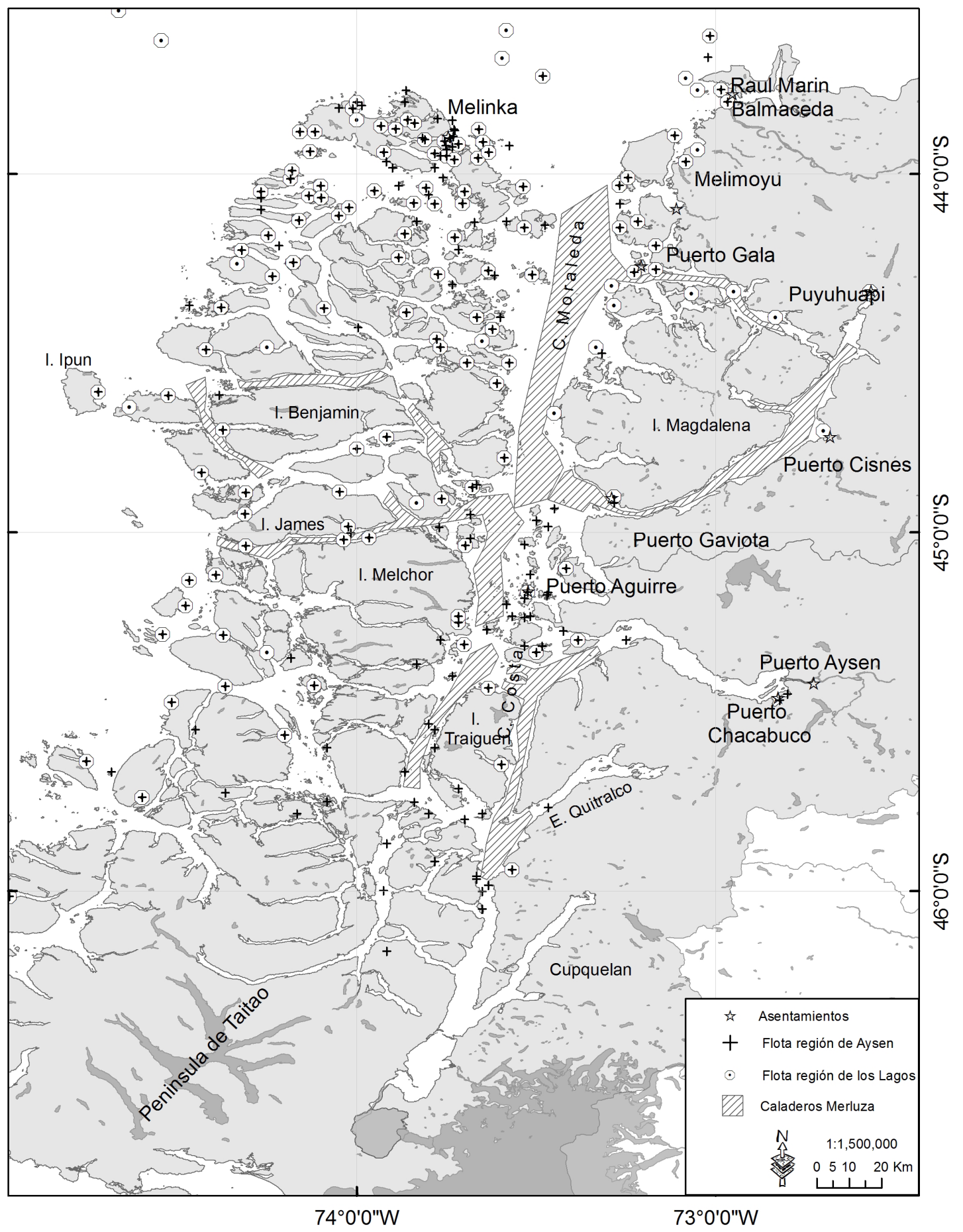

Fig. 6. Localización de los sectores de operación de la flota extractiva de recursos bentónicos de las regiones de Los Lagos y Aysén, y principales caladeros de merluza (polígonos achurados) en el litoral norte de la región de Aysén. 
de trucha arco iris se habrían estado hibridizando con poblaciones de la misma especie previamente introducidas para fines recreacionales (Consuegra et al. 2011).

Los impactos de los contingentes anádromos de las poblaciones ya asilvestradas y/o de los grupos escapados regularmente desde los centros de acuicultura sobre las poblaciones nativas de peces $e$ invertebrados han sido pobremente estudiados, tanto en el Litoral de Aysén como en otras zonas costeras del sur de Chile (Niklitschek et al. 2013; Sepúlveda et al. 2013; Soto et al. 2001). Estos impactos, sin embargo, parecen alcanzar gran magnitud. Sólo en el fiordo Aysén, Niklitschek et al. (2011) estimaron un consumo potencial de más de $11.000 \mathrm{t} \cdot \mathrm{año}^{-1}$, afectando, principalmente, crustáceos (Munida spp.) y peces pelágicos, tales como pejerrey Odontesthes regia y sardina austral Sprattus fuegensis.

\section{c. La Acuicultura}

Los primeros registros de la acuicultura en Aysén datan de 1970, cuando el Instituto de Fomento Pesquero instaló sus primeras balsas de cultivo experimental de moluscos en Isla Teresa (González et al. 1977). La salmonicultura fue, sin embargo, la única actividad acuícola que llegó a consolidarse a nivel industrial en esta misma zona. Su desarrollo fue directa e indirectamente estimulado por el Estado de Chile a partir de los años 80s, incluyendo el financiamiento de un programa piloto, desarrollado por Fundación Chile en Puerto Chacabuco (O'Ryan et al. 2010). Ya en 1991 existían alrededor de 400 concesiones en trámite y se producían más de 680 tons de salmones y truchas (Sernapesca, 1994). Hacia 2008 existían más de 2000 concesiones en trámite (Molinet et al. 2008), 600 centros inscritos (Sernapesca, 2009) y una producción de 209.000 tons, finalizando lo que puede entenderse como la primera fase de expansión de la salmonicultura en el área de estudio. Como consecuencia de la crisis sanitaria derivada del virus ISA (Godoy et al. 2008), desde el año 2011 se hace evidente una segunda fase de expansión, en la cual gran parte de la recuperación y crecimiento post-crisis de la industria del salmón se concentra en el Litoral Norte de Aysén (Niklitschek et al. 2013). De esta manera, la producción de salmónidos en el Litoral Norte de Aysén se eleva fuertemente a partir de 2012, alcanzando un nivel promedio de 403.700 tons para el quinquenio 2012-2016, con un total de 724 centros inscritos para tales fines en 2016 (Fig. 7). Cabe resaltar que este registro de biomasa producida es inédito por lejos en el LNA (ver Fig. 2). Además, dado el nivel promedio de producción por centro, es posible pensar que no todos estos centros están siendo utilizados a plenitud y que, aun sin autorizar nuevos centros, la producción regional podría verse duplicada en la próxima década.

Siguiendo a Niklitschek et al. (2013), los principales impactos ambientales, de carácter local y regional, asociados a la segunda fase de expansión de la salmonicultura en el Litoral Norte de Aysén pueden ser resumidos como sigue: (i) enriquecimiento orgánico, perturbación física y reducción de la biodiversidad bajo las balsas jaula, afectando una superficie estimada de 1.278 ha en el año 2010; (ii) Efectos locales, escasamente evaluados, de la liberación de >140 t.año-1 de antibióticos y otros productos químicos; (iii) efectos adversos sobre la fauna nativa por efecto de su depredación, estimada en 2.300 t.año ${ }^{-1}$ al año 2010, competencia o transmisión de enfermedades de salmones escapados; (iv) impactos, no bien evaluados ni estudiados, de la liberación de nutrientes al ecosistema, la que ya superaba las $12 \times 10^{3} \mathrm{t}$ de nitrógeno, y las $1,6 \times 10^{3} \mathrm{t}$ de fósforo en el año 2010.

\section{DISCUSIÓN Y CONCLUSIONES.}

El rico patrimonio ambiental del Sistema de Fiordos y Canales Nor-Patagónicos que posee una superficie de 5.161.387 ha de áreas protegidas ha sido intensamente explotado durante los últimos 200 años. Es probable que este patrón de explotación no haya sido diferente a lo que conocemos de Chile, sin embargo, debido a lo acelerado de los cambios y a que la zona permanece relativamente inhabitada éstos son más evidentes sobre el paisaje con baja densidad demográfica. Paradojalmente pese a su riqueza en recursos naturales la evidencia sugiere que el LNA refleja una pobre valoración social-ambiental a nivel país, lo que se puede explicar debido a su desconocimiento, por la difícil y costosa accesibilidad que presenta para quienes no buscan explotar sus recursos naturales. 


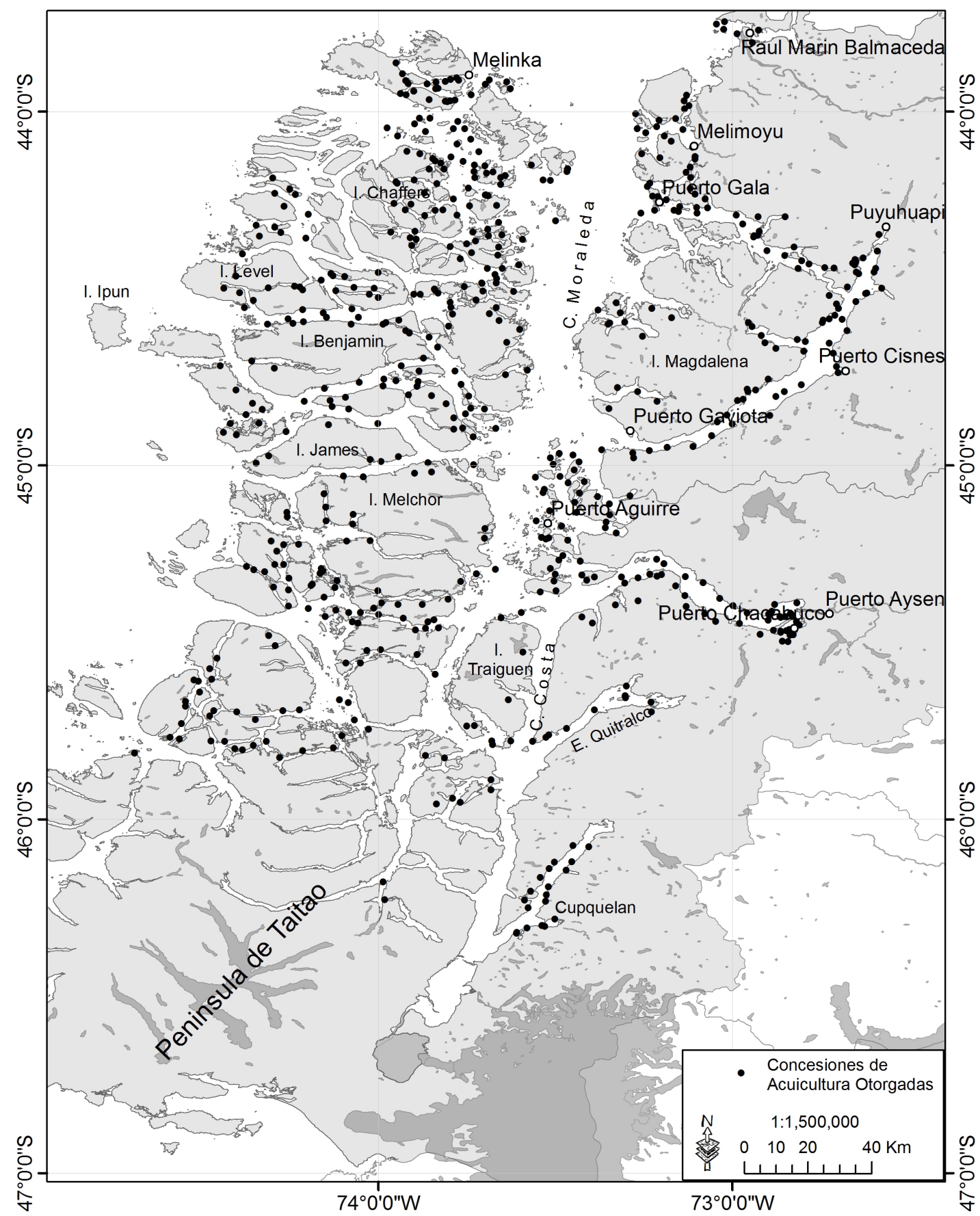

Fig. 7. Localización geográfica de las concesiones de acuicultura otorgadas en el litoral norte de la región de Aysén.

No obstante, la valoración económica de algunas de sus actividades productivas más conspicuas como la acuicultura de salmónidos, la pesca de erizos y la pesca de merluza del sur (que de manera global en Chile, durante 2015 exportaron alrededor de MMUS\$ 7.500, MMUS\$ 121 y US\$ 190, respectivamente) (https://www. cooperativa.cl/noticias/site/artic/20160523/ 
asocfile/20160523163310/idicadores_primer_ trimestre_2016.pdf), la región mantiene índices de competitividad local bajos (Molinet et al. 2014), explicado por un bajo desarrollo manufacturero y una desigual distribución de los ingresos.

Dado el patrón de explotación observado, la relación de los usuarios con el LNA puede ser analizada en el marco de un sistema socioecológico (Ostrom, 2007, 2009), ya que se puede identificar un sistema de recursos (el LNA), los recursos (el ciprés, los mamíferos marinos, los peces $e$ invertebrados) y los usuarios (taladores, peleteros, pescadores, mariscadores, acuicultores), aunque en un contexto de débil gobernanza.

De acuerdo a la selección de variables de segundo orden propuestas por Ostrom (2009) (Tabla 2), este sistema presenta un número de usuarios desconocido e ilimitado (U1), hacheros, peleteros, mariscadores (con baja escolaridad) y en el último tiempo técnicos y profesionales de la acuicultura (U2), cuya historia de uso se limita principalmente a la explotación (U3). Su comportamiento migratorio (incluso en la acuicultura) los asemeja a nómades (U4), cuyos liderazgos locales fueron evolucionando pasando de ser dependientes de un armador (ciprés, pieles y pesca), a ser trabajadores independientes guiados por un presidente de sindicato (pesca), y en muchos casos pasar a ser trabajadores plenamente asalariados (acuicultura) (U5). La heterogeneidad de los usuarios y los objetivos económicos parecen haberse impuesto sobre el capital social (U6), particularmente durante la explotación del ciprés y luego desde los años 1970s cuando se promovieron las exportaciones en Chile (Ffrench-Davis, 2002). La comprensión mental de quienes se asentaron en el LNA fue bien descrita por Marticorena (2009) (U7), observando una relación con el ecosistema que les permitía ocupar el paisaje y admirarlo. Aparentemente, estos modelos mentales fueron abruptamente perturbados por los cambios introducidos en el modelo económico en los años 1970s (Ffrench-Davis, 2002), promoviendo una explotación más competitiva, basada en diversos recursos (U8) y con cambios tecnológicos significativos (U9) que incrementaron exponencialmente el esfuerzo y el impacto sobre los recursos naturales marinos.

En un contexto más global Ostrom (2007) sugirió que las variables U1, U5, U6, U7 y U8 son frecuentemente identificadas como efectos positivos o negativos para la autorregulación de los usuarios en el manejo de un recurso y que en sistemas autorregulados la probabilidad de tener éxito en el manejo es mayor. En el caso del LNA, estas variables muestran efectos negativos para el manejo de recursos y no se observa evidencia de autorregulación, lo que explica la relación de los usuarios con este sistema y el patrón de explotación adoptado sobre este sistema de recursos.

Los antecedentes presentados sugieren que el patrón de explotación pasado y actual del LNA pone en riesgo la sustentabilidad del sistema de recursos y que se debe cambiar la aproximación empleada hasta ahora, basada en el uso oportunista, intensivo y pobremente regulado de estos ecosistemas. No obstante, a pesar de la severidad de las perturbaciones introducidas al LNA en los últimos 200 años, el sistema ha mostrado una cierta resiliencia, probablemente favorecido por su difícil acceso y la baja cantidad de habitantes.

Sin embargo, bajo un escenario de mayores cambios y perturbaciones, globales y locales, parece clave avanzar en mecanismos de regulación que reduzcan las probabilidades de alcanzar situaciones indeseables e irreversibles. Por ejemplo, ante la amenaza inminente de nuevos aumentos en los niveles de producción de la acuicultura, no se debe esperar contar con estudios que nos permitan estimar capacidades de carga con niveles aceptables de certidumbre. Por el contrario, se debe limitar todo incremento en producción y/o descargas hasta no conocer la capacidad de asimilación de las mismas por este ecosistema.

Al considerar nuevas regulaciones, no parece razonable limitarse a aquellas que surgen desde el Estado, en un enfoque "top-down", las que poseen una mayor probabilidad de no poder ser implementadas dadas las dificultades propias del aislamiento y heterogeneidad social y ambiental del área de estudio. Creemos, entonces, necesario considerar y promover, además, la autorregulación de los usuarios. Esto último implica fortalecer el capital social, a través de la educación y la valoración del medio ambiente, entre otras cosas. Finalmente, para cada actividad productiva, junto con los indicadores de desempeño ambiental se debe incluir indicadores sociales y de gobernanza, que permitan evaluar el compromiso de los usuarios por mejorar su relación con el medioambiente. 
Tabla 2. Variables de segundo orden del subsistema Usuarios (U) en un contexto de análisis de sistemas socioecológicos de la explotación del LNA, de acuerdo a Ostrom (2007). * variables clave que pueden ser asociadas con auto-organización.

\begin{tabular}{ll}
\hline $\begin{array}{l}\text { Variables de segundo orden del } \\
\text { susbsistema Usuarios }\end{array}$ & Característica \\
\hline
\end{tabular}

U1- Número de usuarios*

U2- Atributos socioeconómicos de los usuarios

U3- Historia de uso

U4- Localización

U5- Leadership/emprendimiento*

U6- Normas/ capital social*

U7- Conocimiento del SES/modelos*

U7- Conoci
mentales

U8- Importancia/Dependencia del recurso* Parcial, en sistema de alta productividad que ofrece alternativas.

U9- Tecnología usada

Rápida evolución tecnológica

Hacheros, peleteros, pescadores artesanales con baja escolaridad (entre 4 y $8 \mathrm{vo}$ año de educación). Técnicos y profesionales de la acuicultura

Historia de explotación de recursos naturales (madera, pieles, mariscos, peces)

Hacheros, peleteros y pescadores nómades, provenientes de otras regiones. Acuicultura remota (profesionales técnicos y profesionales insertados)

Liderazgos basados en relaciones comerciales (armadores, compradores). Sindicatos de pescadores. Alto emprendimiento económico.

Estandard ético heterogéneo, agrupados para hacer más eficiente la explotación, con comportamiento de reciprocidad desconocida. (Marticorena, 2009)

Conocimiento del sistema en un contexto de explotación. Explotación del espacio

\section{AGRADECIMIENTOS}

Los autores agradecen a los pobladores y pobladoras de Islas Guaitecas (Melinka y Repollal) quienes con sus vivencias enriquecieron este trabajo. Un particular agradecimiento a Don Fernando Cuevas por las conversas con mate. Dos revisores anónimos contribuyeron a mejorar este artículo.

\section{BIBLIOGRAFÍA}

Acevedo, J., Aguayo-Lobo, A., Brito, J. L., Torres, D., Cáceres, B., Vila, A.,... \& Acuña, P. (2016). Review of the current distribution of southern elephant seals in the eastern South Pacific. New Zealand Journal of Marine and Freshwater Research, 50(2), 240-258.

Aranguiz, E. (1992). Los pescadores de Merluza Austral del Grupo Gala y alrededores. Informe de investigación, Aysén.
Araya, M., Niklitschek, E. J., Secor, D. H., Piccoli, P. M. (2014). Partial migration in introduced wild chinook salmon (Oncorhynchus tshawytscha) of southern Chile. Estuarine, Coastal and Shelf Science, 149, 87-95.

Barros, J. M. (1981). Expedición al Estrecho de Magallanes en 1553. Declaración del Estrecho de Magallanes. Expedición de Francisco de Ulloa. Anales del Instituto de la Patagonia, 12, 31-40.

Basulto, S. (2003). El largo viaje de los salmones. Una crónica olvidada. Santiago, Chile: Maval.

Bizama, G., Torrejón, F., Aguayo, M., Muñoz, M.D., Echeverría C., Urrutia, R. (2011). Pérdida y fragmentación del bosque nativo en la cuenca del río Aysén (PatagoniaChile) durante el siglo XX. Revista de Geografía Norte Grande, 49, 125-138

Bluth, A., Espinoza, L., Guzmán, C., Hidalgo, C., Martinez, S., Mellado, M.,... \& Tang, M. (2003). La acuicultura en Chile. Santiago, Chile: TechnoPress.

Cárdenas, A. (1971). Los Guaitequeros: Personajes folklóricos de Chiloé. Rancagua, Chile. 
Chambeaux, J., Miche, 1. F., \& Retamales, A. (2009). Escafandras bajo el Mar. Santiago, Chile: Editorial Cuarto Propio.

CIREN (2010) Determinación de la erosión potencial y actual del territorio de Chile Informe Final Proyecto InnovaChile 06CN121AM-12. Centro de Información de Recursos Naturales (CIREN), Santiago, Chile

Consuegra, S., Phillips, N., Gajardo, G., \& de Leaniz, C. G. (2011). Winning the invasion roulette: escapes from fish farms increase admixture and facilitate establishment of non-native rainbow trout. Evolutionary Applications, 4 660-671.

Corporación Nacional Forestal (1999). Catastro y evaluación de recursos vegetacionales nativos de Chile, Santiago. Universidad Austral de Chile, Pontificia Universidad Católica de Chile, Universidad Católica de Temuco.

Cruz, G., \& Lara, A. (1981). Tipificación, cambio de estructura y normas de manejo para ciprés de las Guaitecas (Pilgerodendron uvifera D. Don Florin) en la isla Grande de Chiloé. Santiago, Chile. Universidad de Chile.

Donoso, C. (1995). Bosques Templados de Chile y Argentina: Variación, estructura y dinámica. Santiago, Chile: Editorial Universitaria.

Emperaire, J. (1963). Los nomades del mar. Santiago, Chile: Ediciones de la Universidad de Chile.

Fasola, L., Chehébar, C., Macdonald, D. W., Porro, G., \& Cassini, M. H. (2009). Do alien North American mink compete for resources with native South American river otter in Argentinean Patagonia?. Journal of Zoology, 277, 187-195

Fasola, L., Muzio, J., Chehébar, C., Cassini, M., \& Macdonald, D. W. (2010). Range expansion and prey use of American mink in Argentinean Patagonia: dilemmas for conservation. European Journal of Wildlife Research, 57, 283-294.

Ffrench-Davis, R. (2002). El impacto de las exportaciones sobre el crecimiento de Chile. Revista de la Cepal, 76, 143160.

García, P. (1766). Diario del viaje y navegación hecho por el padre Joseph García de la Compañía de Jesús desde su misión de Kailín, en Chiloé, hacia el sur. Año 1766. En Von Murr, Gottlieb (1811). Nachrichten von verschiedenen Landern des spanischen Amerika (pp. 506-598). Halle: Verlegt bev Joh. Christian Hendel.

Glime, J. M. (2007). Economic and Ethnic Uses of Bryophytes, In Committee, E. (Ed.), Flora of North America (pp. 14-41). New York: Oxford.

Godoy, M. G., Aedo, A., Kibenge, M. T. J., Groman, D. B., Yason, C. V., Grothusen, H.,... \& Kibenge, F. S.
B. (2008). First detection, isolation and molecular characterization of infectious Salmon anaemia virus associated with clinical disease in farmed Atlantic salmon (Salmo salar). BMC Veterinary Research, 4, 28.

González de Molina, M. (1993). Historia y medio ambiente. Madrid: Eudemo.

Gonzalez, M. L., Hernandez, V. J., \& Santa Cruz, G. S. (1977). Algunos aspectos de la tecnologia de los cultivos marinos en Chile. Simposio FAO/CARPAS sobre Acuicultura en America Latina. Montevideo (Uruguay), 26 Nov 1974.

González-Espinosa, M., Ramírez-Marcial, N., Newton, A. C., Rey-Benayas, J. M., Camacho-Cruz, A., Armesto, J. J., \& Alvarez-Aquino, C. (2007). Restoration of forest ecosystems in fragmented landscapes of temperate and montane tropical Latin America, In A. C. Newton (Ed.), The forests of montane Mexico and temperate South America (pp. 335-369). Wallingford, UK: CABI.

Hucke-gaete, R., Osman, L. P., Moreno, C. A., Findlay, K. P., \& Ljungblad, D. J. (2004). Discovery of a blue whale feeding and nursuring ground in southern Chile. Proceeding of the Royal Society B: Biological Sciences, 271 S170-S173.

Iriarte, A., Lobos, G. A., Jaksic, F. M. (2005). Invasive vertebrate species in Chile and their control and monitoring by governmental agencies. Revista Chilena de Historia Natural, 78 143-151.

Jaksic, F. M., Iriarte, A., Jiménez, J., \& Martínez, D. (2002). Invaders without frontiers: crossborder invasions of exotic mammals. Biological Invasions, 4, 153-173.

Lancelloti, D., \& Vázquez, J. (2000). Zoogeografía de macroinvertebrados bentónicos de la costa de Chile: contribución para la conservación marina. Revista Chilena de Historia Natural, 73.

Lodge, D. M. (1993). Species invasions and deletions: Community effects and responses to climate and habitat changes. In P. M. Kareiva, J. G. Kingsolver, R. B. Huey (Eds.), Biotic Interactions and Global Change (pp. 367-387). Massachusetts, Estados Unidos: Sinauer Associates, Sunderland

Marticorena, F. (2009). A pura memoria: Conocimientos y significados de la naturaleza en las localidades de Melinka y Repollal, litoral norte de la región de Aysén (p. 195).Valdivia. Universidad Austral de Chile.

Martinic, M. (2004). Archipielago Patagonónico: La última frontera. Punta Arenas: La Prensa Austral.

Martinic, M. (2005). De la Trapananda al Aysén: Una mirada reflexiva sobre el acontecer de la Región de Aysén desde 
la prehistoria hasta nuestros días 1 st ed. Santiago: Pehuen.

Medina, G. (1997). A comparison of the diet and distribution of southern river otter (Lutra provocax) and mink (Mustela vison) in Southern Chile Journal of Zoology, 242 291297.

Molinet, C., Arévalo, A., Díaz, M., Díaz, P. (2008a). Uso del borde costero en el mar interior de la región de Aysén y de Los Lagos: escalas e interacción de los procesos de pesca y acuicultura, in: Lovatelli, A., Farías, A., Uriarte, I. (Eds.), Estado actual del cultivo y manejo de moluscos bivalvos y su proyección futura: factores que afectan su sustentabilidad en América Latina pp. 237-247). Taller Técnico Regional de la FAO. 20-24 de agosto de 2007, Puerto Montt, Chile. FAO Actas de Pesca y Acuicultura. No. 12. Roma, FAO.

Molinet, C., Barahona, N., Yannicelli, B., González, J., Arévalo, A., Rosales, S. (2011). Statistical and empirical dentification of multiespecies harveting zones to improve monitoring, assessment, and management of benthic fisheries in southern Chile. Bulletin of Marine Science, 87 (3), 351-375.

Molinet, C., Fuentealba, M., Arevalo, A., Barahona, N., Ariz, L., González, J., . . . Paredes, C. (2008b). Diagnostico biológico - pesquero para recursos bentónicos de la zona contigua, X y XI región (p. 288).Valparaíso. Subsecretaría de Pesca.

Molinet, C., Niklitschek, E. (1995). Diagnóstico y localización nuevos centros poblados litoral norte de Aysén: Recursos pesqueros y Acuicultura. Universidad Austral de Chile, Coyhaique (p. 41).

Molinet, C., Niklitschek, E., Coper, S., Diaz, M., Diaz, P., Fuentealba, M., Marticorena, F. (2014). Challenges for coastal zoning and sustainable development in the Northern Patagonian Fjords, Aysén, Chile. Latin american journal of aquatic research, 42 (1), 18-29.

Montiel, D. (2003). Fusilamientos en Chiloé: La pena máxima, 2 ed. Dimar, Puerto Montt.

Moraga, J., Moreno, Z. (1995). Diagnóstico y localización nuevos centros poblados litoral norte de Aysén: Diagnóstico Sociocultural.Universidad Austral de Chile, Coyhaique. 34.

Moreno, C. A., Barahona, N., Molinet, C., Orensanz, J. M. L., Parma, A. M., Zuleta, A. (2006). From crisis to institutional sustainability in the chilean sea urchin fishery in: McClanahan, T., Castilla, J.C. (Eds.), Fisheries Management: Progress toward sustainability pp. 43-67). Blackwell Publishing, U.K.

Niklitschek, E., Soto, D., A., L., Molinet, C., Toledo, P. (2013).
Southward expansion of the Chilean salmon industry in the Patagonian Fjords: main environmental challenges. Reviews in Aquaculture, 5 172-195.

Niklitschek, E. J., Aedo, E., Araya, M., Barría, C., CanalesAguirre, C., Ernst, B., . . . Toledo, P. (2011). Evaluación cuantitativa del estado trófico de salmónidos de vida libre en el Fiordo Aysén, XI región. Informe final proyecto FIP 2008-30. 194 \& Anexos.

Niklitschek, E. J., Secor, D. H., Toledo, P., Valenzuela, X., Cubillos, L. A., Zuleta, A. (2014). Nursery systems for Patagonian grenadier off Western Patagonia: large inner sea or narrow continental shelf? ICES Journal of Marine Science, 71 374-390.

O’Ryan, R., Niklitschek, M., Niklitschek, E., Ulloa, A., Giglo, N. (2010). Trade liberalization, rural poverty and the environment: a case study of the forest and salmon sectors in Chile, in: Cook, J.A., Cylke, O., Larson, D.F. (Eds.), Vulnerable Places, Vulnerable People: Trade Liberalization, Rural Poverty and the Environment pp. 14-41). Northampton, MA: Edward Elgar Publishing.

Oporto, J., Brieva, L., Navarro, R., Turner, A. (1999). Cuantificación poblacional de lobos marinos en el litoral de la X y XI regiones (p. 277).Valdivia. Fondo de Investigación Pesquera.

Orensanz, J. M. L., Parma, A. M., Jerez, G., Barahona, N., Montecinos, M., Elias, I. (2005). What are the key elements for the sustainability of "S-Fisheries"? Insights South America. Bulletin of Marine Science, 76 (2), 527-556.

Ostrom, E. (2007). A diagnostic approach for going beyond panaceas. Proceedings of the National Academy of Sciences, 104 (39), 15181-15187.

Ostrom, E. (2009). A General Framework for Analyzing Sustainability of Social-Ecological Systems. Science, 325 (5939), 419-422.

Otero, L. (2006). La huella del fuego: Historia de los bosques nativos, poblamiento y cambios en el paisaje del sur de Chile. Santiago: Pehuen.

Pagnoni, G., Garrido, J., Marín, M. (1986). Impacto económico y ambiental del visón, Mustela vison (Schreber, 1877) en el norte de la Patagonia. CENPAT-CONICET, Dirección de Fauna Silvestre, Provincia de Chubut, Argentina.

Pescador, M., Díaz, S., Peris, S. (2012). Abundances of waterbird species on lakes in Argentine Patagonia as a function of season, lake size and the presence of mink. Hydrobiologia, 697 111-125.

Pickard, G. L. (1971). Some physical oceanographic features of inlets of Chile. Journal of Fisheries Research Board of 
Canada, 28 1077-1106.

Pisano, E. (1977). Fitogeografla de Fuego-Patagonia Chilena. I.- Comunidades vegetales entre las latitudes $52^{\circ}$ y $56^{\circ}$. Anales del Instituto de la Patagonia, 8 121-250.

Plaza, J. L. (2001). Dinámica de renovales de ciprés de las Guaitecas (Pilgerodendron uviferum D. Don Florin) en la zona de Lago Vargas, Provincia de Capitán Prat, XI Región (p. 78).Valdivia, Chile. Universidad Austral de Chile.

Quintanilla, V., Cadiñanos, J., Lozano, P. (2015). Degradaciones actuales en ecosistemas nordpatagónicos de Chile, derivadas de los incendios de bosques durante el siglo pasado. Tiempo y Espacio, 21, 6-24

Quiroz, D. (2014). Etnografía histórica de la planta ballenera de Isla Guafo [1921-1937]. Magallania (Punta Arenas), 42, 81-107.

Rozzi, R., Sherriffs, M. (2003). El Visón (Mustela Vison Schreber, Carnivora: Mustelidae), un Nuevo Mamífero Exótico para la Isla Navarino. The Mink (Mustela Vison Schreber, Carnivora: Mustelidae), New Alien Mammal for Navarino Island. 97-104.

Ruiz, J., Schlatter, R., Bucher, D. (1996). Estudio de la situación del visón (Mustela vison, Schreber 1777) y su impacto sobre las comunidades autóctonas de la X Región, como aporte a la protección y recuperación de Áreas Silvestres Protegidas del Estado. Corporación Nacional Forestal, X Región, Puerto Montt, Chile 21.

Sade, K., Pérez, L. (2009). El impacto humano sobre el paisaje arqueológico en la Cuenca del Río Aysén. In: $\mathrm{SCCH}$ Actas del VIII Congreso de Historia Social y Política de la Patagonia argentino chilena (p 266-274). Secretaría de Cultura del Chubut, Rawson (Argentina),

SAG (1999). El Visón (Mustela vison). Coyhaique, Chile: Cartilla de Servicio Agrícola y Ganadero.

Sandoval, R. (1994). Estudio ecológico del visón asilvestrado (Mustela vison, Schreber) en la XI Región.Valdivia, Chile. Universidad Austral de Chile.

Schüttler, E., Klenke, R., McGehee, S., Rozzi, R., Jax, K. (2009). Vulnerability of ground-nesting waterbirds to predation by invasive American mink in the Cape Horn Biosphere Reserve, Chile. Biological Conservation, 142 1450-1460.

Sepúlveda, M., Arismendi, I., Soto, D., Jara, F., Farias, F. (2013). Escaped farmed salmon and trout in Chile: Incidence, impacts, and the need for an ecosystem view. Aquaculture Environment Interactions, 4 273-283.

Sernapesca (1990). Anuario Estadistico de Pesca.Valparaiso. Servicio Nacional de Pesca.

Sernapesca (1992-2010). Anuario estadístico de pesca. http:// www.sernapesca.cl/index.php?option=com_remositor $y \&$ Itemid $=54 \&$ func $=$ select\&id $=2$.

Sernapesca (1994). Anuario Estadistico de Pesca.Valparaiso. Servicio Nacional de Pesca.

Sernapesca (2009). Anuario Estadistico de Pesca.Valparaiso. Servicio Nacional de Pesca.

Sielfeld, W. (1983). Mamíferis Marinos de Chile. Santiago: Ediciones Universidad de Chile.

Silva, N., Calvete, M., Sievers, H. A. (1998). Masas de agua y circulación general para algunos canales Australes entre Puerto Montt y Laguna San Rafael, Chile (Cimar-Fiordo 1). Ciencia y Tecnología del Mar, 21 17-48.

Silva, N., Sievers, H., Prado, R. (1995). Características oceanográficas y una proposición de circulación, para algunos canales australes de Chile entre $41^{\circ} 20^{\prime} \mathrm{S}$ y $46^{\circ} 40^{\prime} \mathrm{S}$. Revista de Biologia Marina, 30 (2), 207-254.

Simpson, E. (1870). Exploraciones hechas por la Corbeta Chacabuco al mando del Capitán de Fragata don Enrique M. Simpson en los Archipiélagos de Güaitecas, Chonos i Taitao. Santiago: Imprenta Nacional.

Solari, M. E., Skewes, J. C., Navarro, M., Paillacheo, F. (2012). Historia ambiental de los archipiélagos de la Trapananda (Patagonia septentrional, Chile): desafios para la conservación de la ballena azul. Cuhso, 22 (1), 115-130.

Soto, D., Arismendi, I., González, J., Sanzana, J., Jara, F., Jara, C., . . . Lara, A. (2006). Southern Chile, trout and salmon country: invasion patterns and threats for native species. Revista Chilena de Historia Natural, 79 97-117.

Soto, D., Jara, F., Moreno, C. A. (2001). Escaped salmon in the seas, southern Chile facing ecological and social conflicts. Ecological Applications, 11 (6), 1750-1762.

Spalding, M. D., Fox, H. E., Allen, G. R., Davidson, N., Ferdaña, Z. A., Finlayson, M., . . . Robertson, J. (2007). Marine Ecoregions of the World: A Bioregionalization of Coastal and Shelf Areas. BioScience, 57 (7), 573-583.

Steffen, F. (1910). Viajes de exploración i estudio en la Patagonia Occidental, 1892-1902. Anales de la Universidad de Chile, 2 74-180.

Torrejón, F., Bizama, G., Araneda, A., Aguayo, M., Bertrand, S., Urrutia, R. (2013). Descifrando la historia ambiental de los archipiélagos de Aysén, Chile: El influjo colonial y la explotación económica-mercantil republicana (siglos XVI-XIX). Magallania, 41 29-52.

Vitousek, R. M., D’Antonio, C. M., Loope, L. L., Westerbrooks, R. (1996). Biological invasions as global environmental change. American Scientist, 84 (468-478).

Viviani, C. A. (1979). Ecogeografía del litoral Chileno. Studies 
on Neotropical Fauna and Environment, 14, 65-123.

Zuleta, A., Rubilar, P., Molinet, C., Rosales, S., Barahona, N. (2005). The Fishing Process in Chilean Sea Urchin
Fishery, 2005. International workshop: Management of Sea Urchin Stocks: Sharing Experiences and Perspectives. 